\title{
Family Dispute Resolution from the Perspective of Comparative Law
}

\author{
Miao Chungang ${ }^{1}$ \\ ${ }^{1}$ Department of Political and Law, North China Electric Power University, Baoding, Hebei, China \\ Correspondence: Miao Chungang. Tel: 86-139-3023-9061. E-mail: sdulmiao0753@sina.com
}

Received: July 8, $2018 \quad$ Accepted: July 12, $2018 \quad$ Online Published: July 27, 2018

doi:10.5539/ass.v14n8p153

URL: https://doi.org/10.5539/ass.v14n8p153

\begin{abstract}
Family cases are different from ordinary civil cases in that they have their own ethical solutions. The traditional Chinese law deals with family disputes focusing on reason law, while legal reform uses the legal technical rationality to weaken the ethical attributes. The current reform of the family trials in China is based on the experience of the extraterritorial law, and gives due consideration to the return of the family-based standard, paying attention to the rights of under-age children. Around this goal, issues such as the resolution principles and procedures of family disputes should be adjusted.
\end{abstract}

Keywords: family cases, reason law, modern law, reform

\section{Introduction}

From ancient to modern, family disputes are related to morality. The resolution of family disputes fully demonstrates the power unifying the rule of virtue and of law. The settlement of traditional Chinese family disputes has been implementing the shaping of a good family style and paying attention to the power of moral education. In the current new era, China government has repeatedly raised the importance of the family tradition construction and called for "focusing on the family, family education, family tradition and family civilization construction." Under this guidance, the Supreme Court has fully promoted the reform of the family trial method, and Hebei Province has also decided 2018 as a year to fully advance the family trial reform. The attention from the central government to local reforms in the family trials shows that this research has a strong practical significance.

The current research on family trial reform is based on judges and procedural law researchers, and the research method is based on the comparative method. The study focuses on the reference to the reform of family litigation procedures in Japan, Germany, the United States, and Australia. The research content is multi-layered and discussed from various perspectives such as the origin of family disputes, family mediation, and family trial reforms. Regarding the causes of family disputes, some scholars started from the family to explore the origin, trying to find the causes of frequent family disputes from the conflict between traditional law and modern law. (Fan, 2011) For the mediation system of the family dispute resolution path, scholars discuss from different perspectives, involving prepositional issues of family mediation procedures, technical construction issues of family mediation, and priority issues in mediation of family dispute resolution. (Chen, 2010) As for the issues of family trial, scholars often start from the path of trial reform, paying attention to the direction and concept of trial reform, and to the construction of family court and the selection and appointment of family judges. (Cao, 2016) In summary, the domestic scholars' comparative study of family disputes focuses on the comparison with extraterritorial laws, and lacks sufficient attention to the traditional reason laws in China. The studies lack attention to the practice of modern civil national adjudication practice and the changes of the family adjudication since the reform and opening up and the content focuses on the study of specific systems, paying little attention to the family dispute resolution concepts and the convergence of multiple dispute resolution mechanisms. (Fan, 2010)

Foreign countries pay more attention to the solution of family disputes. The Dutch scholar Van Remco, the Brazilian scholar Hermes Zaneti, and the legal scholar Emmanuel Jeuland studied issues from the perspective of their family law. Scholars' research has more to do with the tradition of national law and has paid more attention to the protection of the vulnerable groups in the family.

\section{Particularities of Family Cases}

Each discipline or subject area has its own unique problem awareness, unique conceptual tools, and a category system. (Wang, 2013) Family matters in the legal system include marriage, adoption, and guardianship. The 
solution is different from pure property disputes. In addition to the property interest, ethical emotions occupy a considerable proportion in the appeals of the party. Fault determination is very special in family matters. What faults show is not a breach of duty of care. It is more a manifestation of the condemnation of violating family moral obligations.

Family cases have multiple attributes such as ethical law and social law, and their resolution has strong particularity. At present, the value of the home-based standard of society is properly returned. The improvement of the family dispute resolution mechanism will help stabilize family relations, protect the interests of vulnerable groups in family relations, and safeguard judicial justice.

\section{Family Dispute Resolution from the Perspective of Comparative Law}

\subsection{Family Dispute Resolution from the Perspective of Traditional Law}

Around the attributes of reason law, the solution of family cases is determined strictly according to the distance of relatives. The ultimate principle of its treatment is to maintain the three principles and five virtues of feudalism, and maintain the social order with the distinctions between superiority and inferiority. (Cao, 2009) Based on this supreme principle, in divorce cases the law is based on the consideration of maintaining family order, and generally imposes strict restrictions on the freedom of divorce. In order to maintain the patriarchal status of husband power, the husband is allowed to divorce on the grounds of "seven outs", but women right to freedom of divorce is difficult to achieve under the constraints of the family.

For the resolution of family disputes in traditional law, we used to hold a critical view in the past and held that it limits the development of women's individual freedom and independent personality. However, objectively, the family disputes in traditional law are influenced by many factors such as the small-scale peasant economy, politics, and loyalty and filial piety culture.

From the effect of traditional law enforcement, the stability of the family order is sacrificed at the expense of individual freedom, and the interests of under-age children are safeguarded to some extent. (Long, 2002) Under traditional law ethics, individual freedom is subject to the maintenance of family order, and the healthy growth of children is the highest interest of the family. Under the traditional law, there are few situations in which the subjective will of the individual breaks down in the marriage, and the children receive more emotional care under the guardianship of their parents. In order to realize the discipline of children, the law also created a special form of discipline, the right to send punishment.

\subsection{Dispute Resolution from the Perspective of Extraterritorial Comparative Law}

The Anglo-American legal system countries are based on the tradition of case law. The resolution of family disputes is more often done from the perspective of family law and tort law. The latest and more comprehensive family legislation is represented by Australia. The civil law system is based on the tradition of statutory law. The solution of family disputes takes the civil traditional law as the center, and the prosecution of the family case is conducted from the proposition of the protection of the vulnerable group's human rights. The protection of the rights and interests of under-age children is also concerned.

\section{Key Issues to be Paid Attention to in Family Dispute Resolution}

Several basic propositions needed to deal with in the dispute resolution from the experience of domestic and foreign family dispute resolution.

\subsection{Research on the Concept of Family Dispute Resolution}

\subsubsection{The Overall Concept of Family Dispute Resolution}

In family cases, it is important to stress the stability of family relations and to pay attention to the interests of disadvantaged members within the family. This is the basic value of dispute resolution. In the current resolution of family disputes, we must focus on the guiding role of socialist core values and pay attention to the proper return of the family-nased standard. Under the guidance of this concept, attention is paid to the adjustment of legal awareness of different subject identities in dispute resolution. Family dispute resolution is a systematic project. The presiding judge, family investigator and mediator should re-adjust the role of the party as a family case in dispute resolution, pay attention to the reasonable value of the traditional family law culture, and to the value of family stability and the protection of under-age children in the context of the proper return of the family-based standard. (Wang, 2018)

\subsubsection{Research on the Concept of Family Trial}

Family trial reform has preliminary top design. In 2016, the Supreme Court issued the Opinions on the Trial 
Implementation of Family Trial Methods and Work Mechanism Reforms. The Opinions on Establishing a Joint Conference System for the Reform of Family Trial Methods and Work Mechanisms jointly issued by 15 departments including the Supreme Law in 2017 is currently the programmatic document of the family reform. However, objectively speaking, this kind of reform is still not rigorous in litigation theory. There are some controversies regarding the authority of reform subjects and the legitimacy of reform measures. Numerous measures for the reform of family trials reflect the traits of "bold, aggressive, and active actions". However, the legitimacy of the marriage and family law and the procedural law are questionable in the context of not being modified. At the same time, there is also some conflict between the professionalization and elitism of judges and the socialization of family judges. How to treat the relationship between professionalization and socialization in family dispute resolution and how to rationally allocate the responsibilities and authorities of both parties are key topics in the research of trial concepts.

\subsubsection{Research on the Concept of Family Mediation}

Reason law is the essential feature of traditional Chinese law, which esteems the "unification of national law, heavenly principle, and human feelings" in trial practice. As an important system of traditional law, the mediation system has been hailed as "Oriental experience." (Zhu, 2005) The traits of reason law are similar to the social effects focusing on judicial adjudication. The family mediation system is different from ordinary civil mediation, and the discussion on its technical structure has special theoretical and practical values. From a professional point of view, people trained in professional psychology are better able to handle new mediation ideas.

\subsection{Research on Family Dispute Resolution Procedure}

Research on the reform of the family trial procedure: The family case is complex and varied in type. Marriage disputes and other family cases are more special than the others, and there should be differences in the trial procedures and principles for the suitability of the two. The most reasonable choice for the reform of family trials is to enact an independent family trial procedure law. In the reform of the family trial procedure, whether the jurisdiction court, time limit for concluding trials, and the evidence system should be treated differently from the ordinary civil procedure is a subject worthy of study. The selection of judges in family cases has more special requirements on the professional qualities of judges. Promoting the practice of the current pilot court and setting up an independent family trial court and full-time judge are more realistic choices.

Research on the reform of family mediation procedures: Whether the mediation procedure in the family disputes needs to be clearly proposed, whether a relatively independent family mediation office needs to be set up after being proposed, and how the mediators should constitute are propositions worth exploring in depth. Family mediation should invite socialized professionals to participate, but it is worth pondering whether it is necessary to force lawyers to intervene.

\subsection{Research on Family Dispute Resolution Mechanism Under Big Data}

The Supreme Court has issued a report on divorce disputes under big data, being the pioneer for big data analysis of family disputes. The use of big data thinking to analyze the types, causes and focuses of family disputes, and family relations after dispute resolution can better reflect on the path and effectiveness of family dispute resolution, and provide effective data support for the system of family dispute resolution.

\subsection{Research on Judicial Evaluation System of Family Dispute Resolution}

Under the current situation of comprehensively advancing judicial reforms, a scientific and reasonable judicial assessment system can both evaluate the effectiveness of judicial assessment and promote the progress of judicial reform. How to ensure the credibility of the judiciary in the resolution of family disputes and make people feel judicial justice in the case is an important problem in the construction of evaluation system indicators.

\section{Main Points}

To resolve family disputes, the core position of socialist core values should be clarified in the guiding ideology. The guiding ideology emphasizes the appropriate return of the family-based status, and requires that the family's factual basis and dispute resolution procedure basis should be adjusted accordingly. At present, family dispute resolution must absorb the essence of traditional law principles, pay attention to the protection of vulnerable groups during dispute resolution, and solve the problems of perfection and coordination of family mediation system and family trial system. In view of the fact that family dispute resolution is a systematic project, there is a need for a collaborative construction of family law and family non-litigation procedures and litigation procedures in the Civil Code. In the information age, it is of positive practical significance to use judicial big 
data to analyze family disputes and evaluate the effectiveness of the reform of the family dispute resolution mechanism.

The improvement of family dispute resolution mechanism is discussed from the perspective of comparative law. In the comparative study, it is compared with the traditional Chinese law and absorbs the reasonable factors of "reason law". The family disputes that are closely related to the national customs and habits are discussed. The analysis combines the traditions of the "rule of virtue" of ancient China and explores the role of traditional factors such as family traditions and folk culture in solving family disputes. Secondly, the newly revised family procedural law in Taiwan, Australia, and Germany is used to explore its reference significance for family disputes resolution in China.

Researches explore the improvement of the family dispute resolution mechanism from the inter-disciplinary perspectives. Firstly, in the field of law, a framework for settlement is established from the perspective of marriage and family law, procedural law, and legal history to seek the convergence between substantive law and procedural law, and between the legal tradition and the social reality of change; Secondly, the sociological and psychological methods are used to explore the socialization-oriented issues in the family disputes resolution, and the combination of legalization and socialization of change enables the comprehensive management of disputes.

In the information age, with the help of big data, case databases are used as raw data. Sociological statistics methods are used to analyze the causes, types, focuses and solutions of family disputes so as to empirically analyze family cases and reflect the effectiveness of the reform of the family dispute resolution mechanism.

To tackle the family disputes, we should consider two key points. On one hand, the concept of family dispute resolution guidance: how to demonstrate and implement socialist core values is the focus of this topic. The core values have absorbed the essence of the traditional law "rational law" and require the attention on the interests of children and other vulnerable groups in the resolution of family disputes, and properly care for the stability of family relations. On the other hand, Coordination of family dispute resolution mechanisms: In the process of family dispute resolution, how to achieve the convergence of substantive law and procedural law, how to coordinate the relationship between the existing legal system and the reform program, how to coordinate the relationship between mediation procedures and trial procedures, and how to coordinate the relationship between specialization and socialization in dispute resolution are the key points and difficult points of this topic. The coordination of these relationships must be steadily handled in the overall concept of family dispute resolution.

\section{Conclusion}

The resolution of family disputes is the focus of China and foreign countries at present. Although the solution paths are different, they all focus on the path of ethics and the rule of law. As the core concept of traditional legal family dispute resolution, the reason law is consistent with the latest western family reform concept, and should be inherited and developed in the contemporary family dispute resolution in China.

\section{Acknowledgments}

This research was supported by "Hebei Social Science Fund (Grant \# HB18FX019)".

\section{Reference}

Cao, S. J. (2016). An Analysis on the Path of China's Family Judicial Reform. Law Forum, (5).

Cao, X. F. (2009). Personality, personality right and Chinese civil code (p. 87). Science Press.

Chen, A. W. (2010). Research on Family Court System. Peking University Press.

Fan, Y., \& Li, H. (2010). Dispute Resolution-Theory, System, and Skills. Beijing: Tsinghua University Press.

Fan, Z. X. (2011). Reason Law and the Chinese (Revised Edition). Peking University Press.

Long, W. Q. (2002). On the natural right of all persons and its contemporary approach - Also on constitutional order and civil law positivism. Tsinghua Law Journal.

Wang, D. X. (2018). Idea Innovation and Path Adjustment of Family Judgment Reform. Contemporary Jurisprudence.

Wang, L. H. (2013). China Family History (p. 6). Guangdong People Press.

Zhu, Y. (2005). The principle of private law and the modernization of Chinese civil law, jurisprudential study (6th ed.). 


\section{Copyrights}

Copyright for this article is retained by the author(s), with first publication rights granted to the journal.

This is an open-access article distributed under the terms and conditions of the Creative Commons Attribution license (http://creativecommons.org/licenses/by/4.0/). 